\title{
Percepções e atitudes de acadêmicos de fonoaudiologia sobre pessoas com deficiência
}

\author{
Perceptions and attitudes of speech-language \\ pathology and audiology students on people \\ with disabilities
}

\section{Percepciones y actitudes de los académicos de fonoaudiología sobre las personas con discapacidad}

\author{
Vanessa Caroline Bratz* (i) \\ Elenir Fedosse* (D) \\ Pedro García Montenegro** (i)
}

\section{Resumo}

Introdução: Apesar de diferentes esforços para a promoção da inclusão, adaptação e qualidade de vida de pessoas com deficiências $(\mathrm{PcD})$ ainda há barreiras a serem vencidas, principalmente, as atitudinais; tais pessoas continuam sujeitas a diferentes graus e tipos de discriminação. Sabe-se que a formação profissional em Saúde, por exemplo - em Fonoaudiologia - implica em envolvimento com PcD; por isso, a conveniência de se realizar pesquisas, junto a estudantes, sobre esse tema. Objetivo: caracterizar e analisar percepções e atitudes de acadêmicos frente à $\mathrm{PcD}$. Método: estudo exploratório, analítico e quantitativo, realizado por meio de um questionário online, elaborado exclusivamente para este, bem como pelo uso da The Multidimensional Attitudes Scale Toward Persons With Disabilities (MAS), adaptada, visandose conhecer as percepções e as atitudes dos acadêmicos de Fonoaudiologia da Universidade Federal de Santa Maria, acerca de PcD. A coleta ocorreu entre dezembro de 2019 e março de 2020. Os resultados foram analisados por estatística descritiva. Resultados: participaram 36 estudantes; sendo a maioria do sexo feminino, advinda de escolas públicas e com pouco contato com $\mathrm{PcD}$, anteriormente e durante a graduação. Prevaleceu a percepção de não se sentirem amplamente preparados para lidarem com $\mathrm{PcD}$, revelando atitudes como: i) posicionamentos, por vezes, excludentes; ii) sentimentos de tensão, timidez,

* Universidade Federal de Santa Maria - UFSM - Santa Maria - RS, Brasil.

** Universidad de Talca, Talca, Chile.

Contribuição dos autores:

VCB: concepção do estudo; metodologia; coleta de dados; esboço do artigo.

EF: concepção do estudo; esboço do artigo; revisão crítica e orientação.

MGP: concepção do estudo; metodologia e orientação.

E-mail para correspondência: Vanessa Caroline Bratz - vanessacaroline.bratz@hotmail.com Recebido: $26 / 08 / 2020$

Aprovado: 27/01/2021 
vergonha e impotência; iii) intenção para interação com $\mathrm{PcD}$, mas comportamentos contraditórios em relação à mesma. Conclusão: as percepções e as atitudes dos acadêmicos, de modo geral, indicaram pouco contato e insuficiente formação relacionada às deficiências. Sugere-se mais estudos que analisem aspectos singulares da formação acadêmica voltada à PcD.

Palavras-chave: Pessoas com Deficiência; Percepção; Atitude; Fonoaudiologia; Estudantes.

\section{Abstract}

Introduction: Despite different efforts to promote inclusion, adaptation and quality of life for people with disabilities (PwD), there are still barriers to be overcome, especially attitudinal ones. Such people remain subject to different degrees and types of discrimination. It is known that professional training in health, for example - Speech-Language Pathology and Audiology - requires involvement with PwD; therefore, the convenience of conducting research with students on this topic. Objective: to characterize and analyze academics' perceptions and attitudes towards PwD. Method: an exploratory, analytical and quantitative study, carried out by an online questionnaire, designed exclusively for this one, as well as using the Multidimensional Attitudes Scale toward Persons with Disabilities (MAS) adapted, in order to know the perceptions and attitudes of academics of Speech-Language Pathology and Audiology at the Federal University of Santa Maria about the PwD. The collection data occurred between December 2019 and March 2020. The results were tabulated and analyzed by descriptive statistics. Results: 36 students participated; most of them female, coming from public schools, having little contact with PwD before, also in University graduate. A perception of not being widely prepared to deal with PwD prevailed. They revealed as attitudes: i) sometimes excluding positions; ii) feelings of tension, shyness, shame and impotence; iii) intention for interaction, but contradictory behaviours for such. Conclusion: Students' perceptions and attitudes generally indicated little contact and insufficient training related to disabilities. It is suggested that more studies analyze unique aspects of academic training focused on PwD.

Keywords: Disabled Persons; Perception; Attitude; Speech, Language and Hearing Sciences; Students.

\section{Resumen}

Introducción: A pesar de los diferentes esfuerzos para promover la inclusión, la adaptación y la calidad de vida de las personas con discapacidad (PcD), todavía existen barreras que superar, especialmente las actitudinales. Estas personas siguen sujetos a diferentes grados y tipos de discriminación. Se sabe que la formación profesional en salud, por ejemplo - en Fonoaudiología- requiere envolvimiento con PcD; por eso la conveniencia de realizar investigaciones con los estudiantes sobre éste tema. Objetivo: caracterizar y analizar las percepciones y actitudes de los académicos hacia las personas con discapacidad. Método: Estudio exploratorio, analítico y cuantitativo, realizado a través de un cuestionario en línea, desarrollado exclusivamente para este propósito, así como el uso de la The Multidimensional Attitudes Scale Toward Persons With Disabilities (MAS) adaptada, que tuvo como objetivo conocer las percepciones y actitudes de los académicos de Fonoaudiología de la Universidad Federal de Santa Maria sobre las personas con discapacidad. La busca se realizó entre diciembre de 2019 y marzo de 2020. Los resultados fueron tabulados y analizados mediante estadística descriptiva. Resultados: participaron 36 estudiantes; en su mayoría mujeres, provenientes de escuelas públicas, con poco contacto con las personas con discapacidad antes y también durante la educación superior. Tenían la percepción de no sentirse completamente preparados para lidiar con las personas con discapacidad. Revelaron como actitudes: i) posiciones, a veces excluyentes; ii) sentimientos de tensión, timidez, vergüenza e impotencia; iii) intención para la interacción, pero comportamientos contradictorios pala la misma. Conclusión: Las percepciones y actitudes de los estudiantes, en general, indicaron poco contacto e insuficiente formación relacionada con la discapacidad. Se proponen nuevos estudios que analicen aspectos singulares de la formación académica orientada a las personas con discapacidad.

Palabras clave: Personas con Discapacidad; Percepción; Actitud; Fonoaudiología; Estudiantes. 


\section{Introdução}

A deficiência, de acordo com a Classificação Internacional da Funcionalidade Incapacidade e Saúde (CIF):

É uma perda ou anormalidade de uma estrutura do corpo ou de uma função fisiológica (incluindo funções mentais). Na CIF, "o termo anormalidade refere-se estritamente a uma variação significativa das normas estatisticamente estabelecidas (como um desvio de uma média na população obtida usando normas padronizadas de medida) e deve ser utilizado apenas neste sentido". (p. 187) ${ }^{1}$.

Além desta definição, a CIF destaca a funcionalidade como as funções e as estruturas do corpo, bem como as atividades e a participação, caracterizando os aspectos positivos da interação da condição de saúde de uma pessoa com os fatores contextuais (ambientais e pessoais) ${ }^{1}$. Neste sentido, pode-se compreender pessoas com deficiências $(\mathrm{PcD})$ como aquelas que apresentam variedade nas funções ou nas estruturas do corpo e que enfrentam restrições de atividades e participação social.

Sabe-se que o conceito de deficiência tem passado por constante evolução. Houve um tempo em que as PcD eram tidas como portadoras de um corpo marcado pela diferença, compreendidas como inválidas, anormais, monstruosas ou degeneradas, de modo que seus corpos eram entendidos misticamente como resultado da ira ou milagre divino. Posteriormente, entendeu-se que os corpos das PcD deveriam ser "corrigidos", ou seja, submetidos a experiências em busca da normalidade ${ }^{2}$. Nota-se que há uma mudança de paradigma sobre as deficiências, refletida na CIF, a fim de possibilitar uma compreensão profunda das condições de uma pessoa, para além dos fatores incapacitantes (impostos pelas alterações das funções e das estruturas corporais), mas também na relação estabelecida entre as $\mathrm{PcD}$ e seu ambiente, este em sentido amplo, físico, histórico e sóciocultural ${ }^{3 .}$

Tal paradigma implica diferentes necessidades e demandas assistenciais em saúde, educação, lazer e outros aspectos. O Relatório Mundial sobre Deficiência (WRD) refere que "nos próximos anos, a deficiência será uma preocupação ainda maior porque sua incidência tem aumentado"(p-xi)4. Com o aumento de PcD, crescem as dificuldades de inclusão e de adaptação ao meio físico-social; também aumentarão as barreiras, principalmente, as de ordem atitudinais que podem resultar em impedimentos da participação plena e efetiva das $\mathrm{PcD}$ na sociedade em igualdade de condições com as pessoas sem deficiência ${ }^{3}$. Sendo assim, é grande a necessidade de reconhecimento e de atendimento integral às PcD.

Há que se considerar, que as restrições sociais tornam as $\mathrm{PcD}$ invisíveis e, também, produzem nelas sentimentos de incapacidade e de culpa, promovendo, assim, sentimentos de desvalorização5. Portanto, há a necessidade de mudanças, que não devem apenas residir na facilitação de acesso das $\mathrm{PcD}$ aos bens sociais, mas no repensar dos estereótipos e, principalmente, nas atitudes da sociedade ${ }^{6}$. Essas mudanças implicam no distanciamento do reducionismo biomédico (modelo mecanicista saúde-doença), bem como, exigem vasta atuação profissional e oferta de serviços de saúde, para que se amplie as formas de inclusão social e de bem-estar das $\mathrm{PcD}^{4}$. Em virtude disso, vê-se a necessidade de formar profissionais competentes e com excelência para atuarem com as diferentes demandas das PcD. Destaca-se que as competências de um profissional de saúde, dedicado a tais pessoas, devem ir para além de suas áreas de atuação, ou seja, devem focalizar a interdisciplinaridade - condição necessária neste campo de trabalho (cada vez mais exigente e inter-relacionado).

No contexto da demanda permanente para a atuação interdisciplinar junto às $\mathrm{PcD}$, e da necessidade de formar profissionais competentes para lidarem com as diversidades, às quais tais pessoas estão sujeitas, convém refletir sobre como estes aspectos têm sido tratados durante a formação em Fonoaudiologia. Nesse sentido, o objetivo deste estudo foi caracterizar e analisar as percepções e as atitudes dos acadêmicos de Fonoaudiologia da Universidade Federal de Santa Maria frente às PcD.

\section{Método}

Este estudo caracteriza-se como exploratório, analítico-descritivo e de abordagem quantitativa? Trata-se de um dos resultados de uma pesquisa desenvolvidas junto a estudantes de dois cursos de Fonoaudiologia (um no Brasil e outro no Chile) com o objetivo de analisar percepções e atitudes relacionadas às $\mathrm{PcD}$; portanto, foram exclusivamente analisados dados referentes aos estudantes da Universidade Federal de Santa Maria, do Brasil. Participaram acadêmicos dos cinco anos do Curso 
de Fonoaudiologia desta Universidade - turmas ingressantes entre 2015 e 2019 - correspondendo ao total de 112 estudantes. Utilizou-se um cálculo amostral simples, admitindo-se uma proporção estimada de 78 estudantes ( $70 \%$ da população de 112$)$.

Para a coleta dos dados foi enviado um formulário/questionário - Percepção, Conhecimento e Atitudes de Estudantes de Fonoaudiologia sobre $\mathrm{PcD}$ - aos e-mails dos estudantes, os quais foram disponibilizados pela coordenação do referido Curso. O formulário foi gerado eletronicamente na Plataforma de Formulários do Google e deveria ser respondido em um único acesso. Destaca-se que a coleta de dados ocorreu no período de férias - entre dezembro de 2019 e março de 2020 - no intuito de não comprometer a rotina acadêmica dos estudantes. Inicialmente pensou-se no envio de três convites, com intervalo de 15 dias entre um e outro. No entanto, realizou-se o quarto, este enviado pela professora-orientadora deste estudo, em função do baixo número de respostas obtido no período regular da coleta, a fim de atingir o cálculo amostral.

O formulário eletrônico constou de duas partes. A primeira composta por questões que buscaram: i) caracterizar os estudantes; ii) identificar o histórico (pregresso e atual) de contato e/ou atitudes dos estudantes com $\mathrm{PcD}$; iii) verificar a formação acadêmica voltada às $\mathrm{PcD}$; e, iv) sua consequência para a execução de atividades de suporte voluntário junto à referida população. A segunda parte correspondeu aos questionamentos da The Multidimensional Attitudes Scale Toward Persons With Disabilities (MAS) ${ }^{8}$ adaptada pelos propositores da pesquisa anteriormente referida. A $M A S$ contém questões que abordam dimensões - afetivas (14 questões), cognitivas (10) e comportamentais (7). Além disso, apresenta a narrativa de uma situação em que uma pessoa (sem deficiência - Cláudia ou José) passa inesperadamente alguns minutos com uma pessoa usuária de uma cadeira de rodas. As respostas seguem um escalonamento tipo lickert, de 1 a 5 (1 "nada" e 5 "totalmente") indicando os graus de probabilidade da experimentação hipotética. Assim, os participantes deste estudo indicaram como se sentiriam, pensariam e se comportariam na referida situação. Ressalta-se a importância do uso desta escala com estudante de Fonoaudiologia, visto que, na literatura consultada, foram encontradas pesquisas acerca deste tema na Medicina ${ }^{9}$, Enfermagem ${ }^{10}$ e Odontologia ${ }^{11}$.

Esta pesquisa seguiu as recomendações da Resolução $n^{\circ} 466$, de 12 de dezembro de 2012, tendo sido aprovada pelo Comitê de Ética de Pesquisa com Seres Humanos sob o parecer de n ${ }^{\circ}$ 2.975.025.

\section{Resultados}

Os resultados desta pesquisa são apresentados em duas subseções: a primeira relativa à caracterização da população estudada e a segunda voltada às percepções e atitudes dos participantes. Antes, porém, considerou-se pertinente destacar a maior dificuldade encontrada na realização desta, qual seja: a participação dos estudantes, visto que não foi possível alcançar a amostra prevista, não por falta de divulgação e/ou convite, mas possivelmente pelo período (férias acadêmicas) da coleta de dados. A propósito, contou-se, apenas, com a participação de 36 (Tabela 1) dos 78 estudantes indicados pelo cálculo amostral (aproximadamente 16 de cada ano). Assim, obteve-se a participação de 46,15\% dos estudantes do curso, sendo $3,84 \%$ do primeiro ano, $16,66 \%$ do segundo, $6,41 \%$ do terceiro, $14,10 \%$ do quarto e $5,13 \%$ do quinto ano (N:78).

Tabela 1. Estudantes respondentes e respectivos períodos de respostas $(n=36)$

\begin{tabular}{|c|c|c|c|c|c|c|}
\hline \multicolumn{7}{|c|}{ Estudantes } \\
\hline & 10 ano & 20 Ano & $3^{\circ}$ Ano & $4^{\circ}$ Ano & $5^{\circ}$ Ano & Total \\
\hline 10 envio & 1 & 3 & 4 & 2 & 3 & 13 \\
\hline 20 envio & 0 & 0 & 1 & 2 & 1 & 4 \\
\hline $3^{\circ}$ envio & 1 & 0 & 0 & 1 & 0 & 2 \\
\hline $4^{\circ}$ envio & 1 & 10 & 0 & 6 & 0 & 17 \\
\hline Total /\%* & 8,33 & 36,11 & 13,88 & 30,55 & 11,11 & $100 \%$ \\
\hline
\end{tabular}

Legenda: * Porcentagem 


\section{Subseção 1- Caracterização da} população estudada

Na Tabela 2 apresentam-se dados sociodemográficos e econômicos dos participantes, bem como referentes ao sistema de ensino, cursado anteriormente à universidade, constelação familiar e condição atual de moradia. Tais dados foram obtidos por meio das questões do Item I do formulário/questionário - Percepção, Conhecimento e Atitudes de Estudantes de Fonoaudiologia sobre PcD.

Tabela 2. Caracterização dos estudantes de fonoaudiologia da universidade federal de santa maria $(2015-2019)(n=36)$

\begin{tabular}{|c|c|c|c|c|}
\hline CATEGORIA & \multicolumn{2}{|c|}{ Subitem } & Número & Porcentagem \\
\hline \multirow{2}{*}{ Sexo } & \multicolumn{2}{|c|}{ Feminino } & 32 & $88,89 \%$ \\
\hline & \multicolumn{2}{|c|}{ Masculino } & 4 & $11,11 \%$ \\
\hline \multirow{5}{*}{ Idade } & \multicolumn{2}{|c|}{18 anos a 20 e 11 meses } & 15 & $41,67 \%$ \\
\hline & \multicolumn{2}{|c|}{21 a 22 e11 meses } & 13 & $36,12 \%$ \\
\hline & \multicolumn{2}{|c|}{22 a 24 e 11 meses } & 6 & $16,66 \%$ \\
\hline & \multicolumn{2}{|c|}{25 a 26 e 11 meses } & 0 & $0 \%$ \\
\hline & \multicolumn{2}{|c|}{27 a 28 e 11 meses } & 2 & $5,55 \%$ \\
\hline \multirow{2}{*}{ Nível econômico } & \multicolumn{2}{|c|}{ Baixo } & 11 & $30,6 \%$ \\
\hline & \multicolumn{2}{|c|}{ Médio } & 25 & $69,4 \%$ \\
\hline \multirow{4}{*}{ Tipo de Ensino } & \multirow{2}{*}{ Ens. Fundamental } & Público & 23 & $63,88 \%$ \\
\hline & & Privado & 13 & $36,12 \%$ \\
\hline & \multirow{2}{*}{ Ensino Médio } & Público & 21 & $58,34 \%$ \\
\hline & & Privado & 15 & $41,66 \%$ \\
\hline \multirow{3}{*}{ Constelação Familiar } & \multirow{3}{*}{ Número de Irmãos } & 0 a 1 irmão & 26 & $72,23 \%$ \\
\hline & & 2 a 4 irmãos & 9 & $25 \%$ \\
\hline & & $\geq 5$ irmãos & 1 & $2,77 \%$ \\
\hline \multirow{3}{*}{ Condição de Moradia } & & Com amigos & 11 & $30,55 \%$ \\
\hline & & Com família & 16 & $44,45 \%$ \\
\hline & & Sozinho & 9 & $25 \%$ \\
\hline
\end{tabular}


A seguir apresenta-se a Figura 1 - com as questões do Item II do formulário/questionário (para melhor orientação ao leitor); em seguida, apresenta-se a Tabela 3 referente ao histórico de contato (pregresso e atual) e/ou atitudes dos estudantes em relação a $\mathrm{PcD}$ em diferentes contextos.

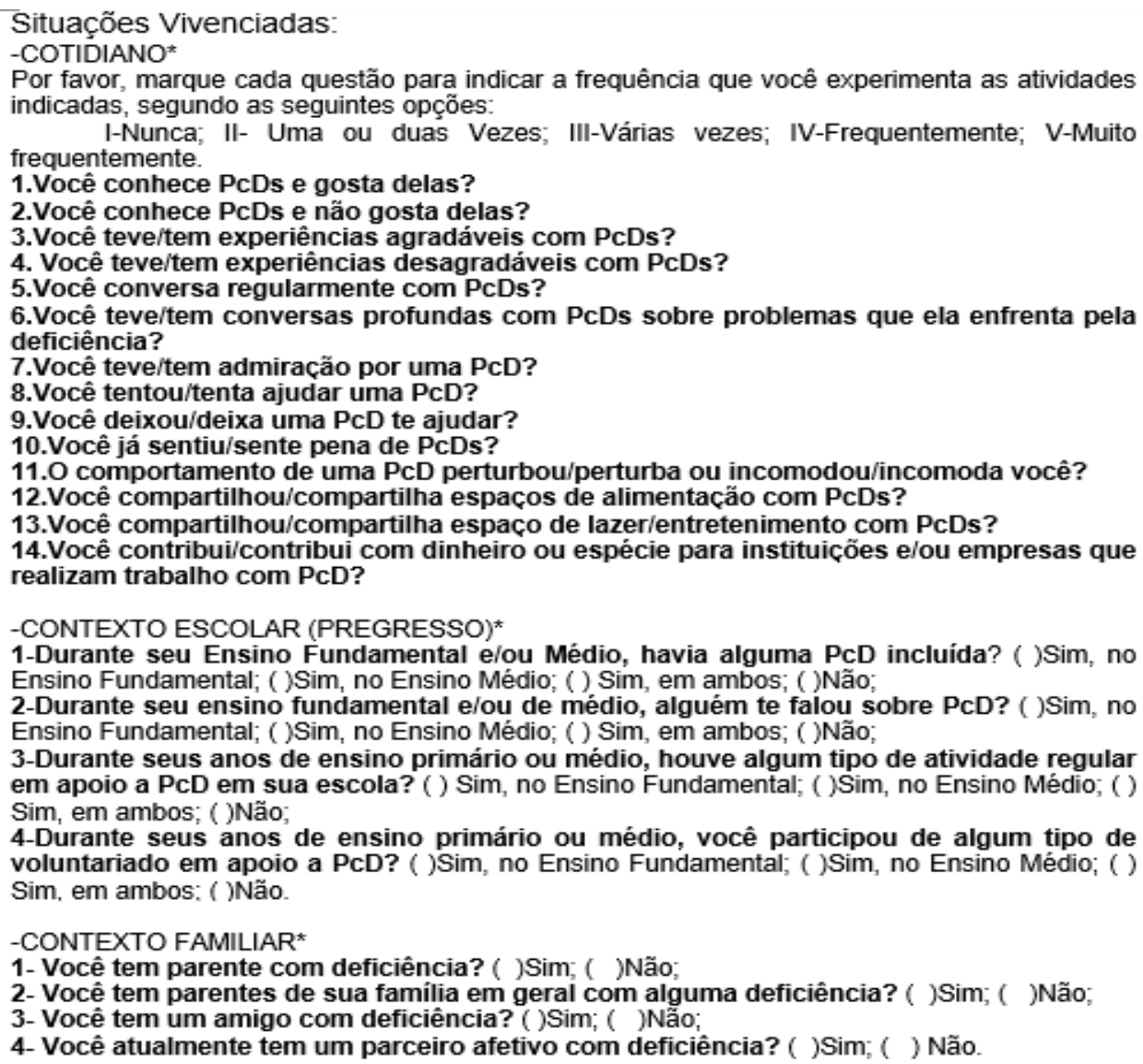

1-Durante seu Ensino Fundamental e/ou Médio, havia alguma PcD incluída? ( )Sim, no Ensino Fundamental; ()Sim, no Ensino Médio; () Sim, em ambos; ()Não;

2-Durante seu ensino fundamental e/ou de médio, alguém te falou sobre PcD? ( )Sim, no Ensino Fundamental; ( )Sim, no Ensino Médio; ( ) Sim, em ambos; ( ) Não;

3-Durante seus anos de ensino primário ou médio, houve algum tipo de atividade regular em apoio a PcD em sua escola? ( ) Sim, no Ensino Fundamental; ()Sim, no Ensino Médio; ( ) Sim, em ambos; ( ) Não-

4-Durante seus anos de ensino primário ou médio, você participou de algum tipo de voluntariado em apoio a PcD? ( )Sim, no Ensino Fundamental; ( )Sim, no Ensino Médio; ( ) Sim, em ambos: ( )Não.

-CONTEXTO FAMILIAR*

1- Você tem parente com deficiência? ( ) Sim; ( )Não;

2- Você tem parentes de sua família em geral com alguma deficiência? ( ) Sim; ( )Não;

3- Você tem um amigo com deficiência? ( ) Sim; ( ) Nấ;

4- Você atualmente tem um parceiro afetivo com deficiência? ( )Sim; ( ) Não.

Fonte: Questionário - Percepção, conhecimento e atitudes de estudantes de Fonoaudiologia sobre PcD.

Figura 1. Item II - identificação do histórico (pregresso e atual) de relação e/ou atitudes dos estudantes com PcD. 
Tabela 3. Histórico (pregresso e atual) dos estudantes relativo ao contato e/ou atitudes com PCD no cotidiano, contexto educacional e contexto familiar $(n=36)$

\begin{tabular}{|c|c|c|c|c|c|c|c|c|c|c|c|}
\hline \multirow{2}{*}{$\begin{array}{l}\text { Situações } \\
\text { Vivenciadas }\end{array}$} & \multirow{2}{*}{ Pergunta } & \multicolumn{10}{|c|}{ Grau dos Acontecimentos } \\
\hline & & $\mathbf{I}$ & $\%$ & II & $\%$ & III & $\%$ & IV & $\%$ & $\mathbf{V}$ & $\%$ \\
\hline \multirow[t]{14}{*}{ Cotidiano } & 1 & 8 & 22,2 & 3 & 8,33 & 9 & 25 & 1 & 2,78 & 15 & 41,6 \\
\hline & 2 & 27 & 75 & 9 & 25 & 0 & 0 & 0 & 0 & 0 & 0 \\
\hline & 3 & 3 & 8,33 & 4 & 11,11 & 10 & 27,8 & 9 & 25 & 10 & 27,8 \\
\hline & 4 & 19 & 52,77 & 14 & 38,9 & 3 & 8,33 & 0 & 0 & 0 & 0 \\
\hline & 5 & 10 & 27,8 & 7 & 19,4 & 8 & 22,2 & 4 & 11,11 & 7 & 19,4 \\
\hline & 6 & 13 & 36,11 & 6 & 16,67 & 6 & 16,67 & 4 & 11,11 & 7 & 19,4 \\
\hline & 7 & 0 & 0 & 2 & 5,55 & 8 & 22,2 & 9 & 25 & 17 & 47,25 \\
\hline & 8 & 0 & 0 & 4 & 11,11 & 13 & 36,11 & 8 & 22,2 & 11 & 30,58 \\
\hline & 9 & 11 & 30,58 & 6 & 16,67 & 11 & 30,58 & 2 & 5,55 & 6 & 16,66 \\
\hline & 10 & 6 & 16,66 & 10 & 27,8 & 15 & 41,6 & 3 & 8,33 & 2 & 5,55 \\
\hline & 11 & 19 & 52,78 & 14 & 38,9 & 2 & 5,55 & 1 & 2,78 & 0 & 0 \\
\hline & 12 & 4 & 11,11 & 2 & 5,55 & 12 & 33,34 & 8 & 22,2 & 10 & 27,8 \\
\hline & 13 & 6 & 16,67 & 3 & 8,33 & 12 & 33,34 & 5 & 13,88 & 10 & 27,8 \\
\hline & 14 & 23 & 63,9 & 7 & 19,4 & 4 & 11,11 & 1 & 2,78 & 1 & 2,78 \\
\hline \multirow{3}{*}{\multicolumn{2}{|c|}{ Contexto Escolar }} & \multicolumn{10}{|c|}{ Opções: } \\
\hline & & \multicolumn{7}{|c|}{ Sim } & \multicolumn{3}{|c|}{ Não } \\
\hline & & a) & $\%$ & & b) & $\%$ & c) & $\%$ & & - & $\%$ \\
\hline & 1 & 6 & 16,66 & & 3 & 8,33 & 10 & 27,8 & & 17 & 47,25 \\
\hline & 2 & 1 & 2,78 & & 4 & 11,11 & 22 & 61,11 & & 9 & 25 \\
\hline & 3 & 4 & 11,11 & & 4 & 11,11 & 2 & 5,55 & & 26 & 72,22 \\
\hline & 4 & 2 & 5,55 & & 2 & 5,55 & 4 & 11,11 & & 28 & 77,78 \\
\hline \multirow{2}{*}{\multicolumn{2}{|c|}{ Contexto Familiar }} & \multicolumn{5}{|c|}{ Opções: } & & & & & \\
\hline & & Sim & $\%$ & & Não & $\%$ & & & & & \\
\hline & 1 & 5 & 13,88 & & 31 & 86,12 & & & & & \\
\hline & 2 & 16 & 44,44 & & 20 & 55,56 & & & & & \\
\hline & 3 & 14 & 38,9 & & 21 & 58,33 & & & & & \\
\hline & 4 & 0 & 0 & & 36 & 100 & & & & & \\
\hline
\end{tabular}

Legenda: I - Nunca; II - Uma ou duas Vezes; III - Várias vezes; IV - Frequentemente; V - Muito frequentemente. 
No que se refere à formação acadêmica em Fonoaudiologia relacionada à $\mathrm{PcD}$, foram levantadas as percepções dos estudantes a partir das asserti- vas presentes no Item III do referido formulário/ questionário (Figura 2), estando os resultados apresentados no Quadro 1.

Por favor, marque cada questão para indicar a formação que você tem recebido durante a graduação sobre Deficiência e Funcionalidade, segundo as seguintes opç̃̃es*:

I- Em franca discordância; II-Geralmente discordo; III-Mais discordo do que concordo; IVConcordo de alguma forma; V-Geralmente concordo; VI-não sei responder, VII-Não realizei prática clínica.

1. A formação teórica é relevante, entendo os conceitos gerais e sua importância para o meu trabalho?

2. Tenho acesso a informaçôes atualizadas e relevantes sobre deficiência?

3. Os professores estão preocupados em oferecer uma visão integrada de funcionalidade, alinhada com o atual desenvolvimento do assunto em nível internacional?

4. A sequência da oferta sobre deficiência é relevante e posso identificá-la claramente na minha formação profissional?

5.Recebo informaçóes das políticas relevantes sobre as deficiências?

6. Posso dizer que minha formação sobre deficiência é apropriada e que minha instituição está preocupada com essas questões?

7. Posso dizer que os acadêmicos da instituição lidam amplamente com o tema da deficiência?

8. Em minhas atividades práticas os direitos das PcDs são respeitados?

9. A formação prática é relevante, interajo com quantidade adequada de PcDs em diversos contextos e de diversas características?

10. Os profissionais com quem tenho interagido em atividades práticas lidam amplamente com a questão da deficiência?

Fonte: Questionário - Percepção, conhecimento e atitudes de estudantes de Fonoaudiologia sobre PcD.

Figura 2. Item III - formação profissional voltada à deficiência

Quadro 1. Formação acadêmica em fonoaudiologia voltada à deficiência. $(N=36)$

\begin{tabular}{lccccccc}
\hline \multirow{2}{*}{ Assertivas } & \multicolumn{6}{c}{ Grau de Concordância referido pelos estudantes: } & \multicolumn{2}{c}{ Outra Manifestação } \\
\cline { 2 - 7 } & I & II & III & IV & V & $\begin{array}{c}\text { Não sei } \\
\text { responder }\end{array}$ & $\begin{array}{c}\text { Não realizei } \\
\text { práticas clínicas }\end{array}$ \\
\hline $1-$ & 1 & 0 & 3 & 9 & 19 & 4 & \\
$2-$ & 2 & 2 & 5 & 9 & 15 & 3 & \\
$3-$ & 1 & 0 & 5 & 7 & 18 & 5 & \\
$4-$ & 1 & 0 & 6 & 6 & 17 & 6 & \\
$5-$ & 3 & 7 & 8 & 10 & 4 & 4 & 14 \\
$6-$ & 1 & 2 & 5 & 10 & 12 & 6 & 12 \\
7 & 0 & 4 & 12 & 10 & 5 & 5 & 10 \\
$8-$ & 1 & 0 & 2 & 5 & 14 & & \\
$9-$ & 0 & 1 & 4 & 10 & 9 & & \\
$10-$ & 0 & 3 & 3 & 8 & 12 & & \\
\hline
\end{tabular}

Legenda: I- Em franca discordância; II- Geralmente discordo; III-Mais discordo do que concordo; IV- Concordo de Alguma forma; VGeralmente concordo. 
Visando conhecer a repercussão da formação acadêmica quanto ao envolvimento com $\mathrm{PcD}$, fora do contexto formativo, foi questionado se os estudantes realizavam ou não voluntariado junto a tais pessoas, buscando-se identificar os fatores que os impediam de realizá-lo. Os dados obtidos foram: apenas dois estudantes $(1,78 \%)$ desenvolviam voluntariado. Já no que se refere às razões que interferiam para o não desenvolvimento, nenhum estudante marcou a opção - não realizo voluntariado porque tem pessoas mais habilitadas para isso -; dois indicaram não ter facilidade para voluntariado; três não tinham interesse (no momento em que a pesquisa foi realizada); 13 indicaram não ter tempo no momento; 16 pensaram, mas não se decidiram a realizar voluntariado; 20 sentiram não estar preparados o suficiente para o voluntariado e 21 indicaram desconhecer instituições que atendiam PcD para realizar este tipo de atividade.

No que se refere ao grau de dificuldade dos estudantes em se relacionarem com PcD de diferentes faixas etárias e de diferentes tipos de deficiência, obteve-se: dois estudantes indicaram que "não poderiam se relacionar com PcD" (um indicou a faixa etária adulto e o outro a idosa como limitantes). Vinte estudantes indicaram que têm "muitas dificuldades para se relacionar" com tais pessoas (seis com crianças, quatro com jovens, cinco com adultos e cinco com idosos); 17 estudantes indicaram "algumas dificuldades" em se relacionar com crianças, 20 com jovens, 20 com adultos e 19 com idosos. Por fim, 13 estudantes indicaram "nenhuma dificuldade" em se relacionar com crianças, $12 \mathrm{com}$ jovens, 10 com adultos e 11 com idosos.

Quanto ao tipo de deficiência, os estudantes demonstraram ter mais dificuldades com pessoas que apresentam problemas de natureza psiquiátrica, sendo que três assinalaram que "não poderiam se relacionar com pessoas com doenças mentais" (psicoses, esquizofrenia, demência entre outras) ${ }^{12}$, 18 indicaram "muitas dificuldades", 12 "algumas dificuldades" e três "nenhuma dificuldade". No que se refere à deficiência visual, 10 estudantes indicaram ter "muitas dificuldades" para se relacionar com pessoas com essa deficiência, 21 "alguma dificuldade" e cinco "nenhuma dificuldade". Já no que refere a PcD congênitas e/ou adquiridas durante o desenvolvimento neuropsicomotor (encefalopatia não progressiva), quatro marcaram "muitas dificuldades", 16 "algumas dificuldades" e 16 "nenhuma dificuldade". Em relação às deficiências adquiridas, dois indicaram "muitas dificuldades", 20 "algumas dificuldades" e 14, "nenhuma". Já em relação à $\mathrm{PcD}$ cognitiva/intelectual, dois marcaram "muitas dificuldades", 20 "algumas dificuldades" e 14, "nenhuma". Quanto à PcD Auditiva, três indicaram "muitas dificuldades", 16 "algumas dificuldades" e 17, "nenhuma”. Já com relação à PcD física, dois marcaram "muitas dificuldades", 13 "algumas dificuldades" e 21, "nenhuma".

\section{Subseção 2 - Percepções e Atitudes dos estudantes sobre $P C D$}

Quanto às dimensões (sentimentos, pensamentos e comportamentos) da experimentação/ situação hipotética, proposta na MAS, a maioria dos estudantes $(66 \%)$ imaginou Cláudia como a protagonista e $31(86,11 \%)$ imaginaram a pessoa com deficiência como sendo um homem (Tabela 4). 
Tabela 4. Dimensões da experimentação hipotética e possibilidades de experimentá-las por estudantes de fonoaudiologia da Universidade Federal de Santa Maria $(n=36)$

\begin{tabular}{|c|c|c|c|c|c|c|c|c|c|c|}
\hline \multicolumn{11}{|c|}{ Graus de probabilidade } \\
\hline Sentimentos: & 1 & $\%$ & 2 & $\%$ & 3 & $\%$ & 4 & $\%$ & 5 & $\%$ \\
\hline Rejeição & 9 & 25 & 12 & 33,33 & 6 & 16,66 & 3 & 8,333 & 6 & 16,66 \\
\hline Impotência & 4 & 11,11 & 9 & 25 & 13 & 36,11 & 5 & 13,88 & 5 & 13,88 \\
\hline Medo & 12 & 33,33 & 8 & 22,22 & 10 & 27,77 & 5 & 13,88 & 1 & 2,77 \\
\hline Chateação & 11 & 30,55 & 11 & 30,55 & 7 & 19,44 & 2 & 5,55 & 5 & 13,88 \\
\hline Culpa & 16 & 44,44 & 8 & 22,22 & 9 & 25 & 1 & 2,77 & 2 & 5,55 \\
\hline Timidez & 2 & 5,55 & 4 & 11,11 & 16 & 44,44 & 11 & 30,55 & 3 & 8,33 \\
\hline Estresse & 16 & 44,44 & 9 & 25 & 8 & 22,22 & 2 & 5,55 & 1 & 2,77 \\
\hline Vergonha & 7 & 19,44 & 6 & 16,66 & 11 & 30,55 & 9 & 25 & 3 & 8,33 \\
\hline Tensão & 4 & 11,11 & 6 & 16,66 & 17 & 47,22 & 6 & 16,66 & 3 & 8,33 \\
\hline Serenidade & 9 & 25 & 15 & 41,66 & 6 & 16,66 & 5 & 13,88 & 1 & 2,77 \\
\hline Nervosismo & 2 & 5,55 & 11 & 30,55 & 11 & 30,55 & 9 & 25 & 3 & 8,33 \\
\hline Depressão & 18 & 50 & 10 & 27,77 & 4 & 11,11 & 2 & 5,55 & 2 & 5,55 \\
\hline Calma & 11 & 30,55 & 11 & 30,55 & 8 & 22,22 & 4 & 11,11 & 2 & 5,55 \\
\hline Descontração & 13 & 36,11 & 10 & 27,77 & 8 & 22,22 & 4 & 11,11 & 1 & 2,77 \\
\hline \multicolumn{11}{|l|}{ Pensamentos: } \\
\hline $\begin{array}{l}\text { Por que não, conhecê-la } \\
\text { melhor? }\end{array}$ & 1 & 2,77 & 5 & 13,88 & 14 & 38,88 & 8 & 22,22 & 8 & 22,22 \\
\hline $\begin{array}{l}\text { Se eu começar a conversa, } \\
\text { ela vai me agradecer }\end{array}$ & 9 & 25 & 9 & 25 & 14 & 38,88 & 4 & 11,11 & $\mathbf{0}$ & 0 \\
\hline $\begin{array}{l}\text { Gosto de conhecer gente } \\
\text { nova }\end{array}$ & 1 & 2,77 & 5 & 13,88 & 15 & 41,66 & 7 & 19,44 & 8 & 22,22 \\
\hline $\begin{array}{l}\text { É possível que nos demos } \\
\text { bem }\end{array}$ & 1 & 2,77 & 0 & 0 & 16 & 44,44 & 10 & 27,77 & 9 & 25 \\
\hline $\begin{array}{l}\text { Ela parece ser uma pessoa } \\
\text { interessante }\end{array}$ & 2 & 5,55 & 5 & 13,88 & 13 & 36,11 & 13 & 36,11 & 8 & 22,22 \\
\hline $\begin{array}{l}\text { Eu posso fazer com que ela } \\
\text { se sinta confortável }\end{array}$ & 1 & 2,77 & 2 & 5,55 & 14 & 38,88 & 12 & 33,33 & 7 & 19,44 \\
\hline Ela parece amigável & 1 & 2,77 & 0 & 0 & 16 & 44,44 & 9 & 25 & 10 & 27,77 \\
\hline $\begin{array}{l}\text { Ela vai gostar de me } \\
\text { conhecer }\end{array}$ & 3 & 8,33 & 6 & 16,66 & 15 & 41,66 & 9 & 25 & 10 & 27,77 \\
\hline Ela parece uma boa pessoa & 1 & 2,77 & 0 & 0 & 19 & 52,77 & 11 & 30,55 & 5 & 13,88 \\
\hline $\begin{array}{l}\text { Eu posso falar com ela sobre } \\
\text { coisas que nos interessam }\end{array}$ & 1 & 2,77 & 2 & 5,55 & 14 & 38,88 & 11 & 30,55 & 8 & 22,22 \\
\hline \multicolumn{11}{|l|}{ Comportamentos: } \\
\hline Ler jornal ou falar ao celular & 2 & 5,55 & 8 & 22,22 & 15 & 41,66 & 5 & 13,88 & 6 & 16,66 \\
\hline $\begin{array}{l}\text { Encontrar uma desculpa } \\
\text { para sair }\end{array}$ & 7 & 19,44 & 16 & 44,44 & 3 & 8,33 & 7 & 19,44 & 3 & 8,33 \\
\hline Iniciar uma conversa & 0 & 0 & 3 & 8,33 & 20 & 55,55 & 8 & 22,22 & 5 & 13,88 \\
\hline Afastar-se & 15 & 41,66 & 13 & 36,11 & 4 & 11,11 & 3 & 8,33 & 1 & 2,77 \\
\hline Trocar de mesa & 21 & 58,33 & 11 & 30,55 & 2 & 5,55 & 1 & 2,77 & $\mathbf{1}$ & 2,77 \\
\hline Levantar-se e sair & 21 & 58,33 & 11 & 30,55 & 1 & 2,77 & 2 & 5,55 & 1 & 2,77 \\
\hline $\begin{array}{l}\text { Continuar o que estava } \\
\text { fazendo }\end{array}$ & 1 & 2,77 & 5 & 13,88 & 19 & 52,77 & 7 & 19,44 & 4 & 11,11 \\
\hline
\end{tabular}

*Legenda: 1- Nada, é improvável; 2 Algo, é improvável; 3 É bem provável; 4 É altamente provável; 5 É totalmente provável.

\section{Discussão}

O primeiro ponto de análise deste estudo, embora não esteja diretamente relacionado ao seu objetivo, refere-se ao baixo índice de participação dos estudantes. A este respeito, encontrou-se uma pesquisa que avaliou diferentes métodos de coleta de dados (entrevistas, questionários, grupos focais, entre outros) e identificou que o uso de questionário eletrônico tende a resultar em baixos índices de respostas; dentre suas limitações estão o acesso à internet, o grande volume de e-mails ou de endereços eletrônicos inválidos ${ }^{13}$. Em certa medida, os dados deste estudo concordam com o encontrado, 
já que muitos e-mails enviados (total de 14 , do primeiro ao quarto convite) voltaram, diminuindo o número de respondentes.

Outras possíveis interpretações referentes à baixa adesão a este estudo podem estar relacionadas ao período da pesquisa (férias acadêmicas) e ao tempo de graduação. Apesar de a ideia inicial ser a de não atrapalhar as atividades acadêmicas no período letivo, analisa-se que foi uma escolha equivocada, visto que as férias de verão tendem a ser cumpridas efetivamente pelos estudantes. Quanto ao tempo de graduação, considerou-se que estudantes de fase inicial ainda não incorporaram a rotina ensino-pesquisa-extensão do contexto universitário e, também, tendem a apresentar dificuldades de adaptação nessa fase que envolve mudanças ambientais (nova cidade, por exemplo) e comportamentais (novos hábitos de estudo) maior exigência por aquisição de normas e de comportamentos apropriados ao ensino superior, bem como à vida cotidiana (nova moradia e novas formas de convivência). Portanto, o estudante ingressante é convocado a desafios acadêmicos, sociais e interpessoais, além dos voltados à carreira em formação ${ }^{14}$.

Em conformidade com isso e considerando a atual grade curricular do curso de Fonoaudiologia da Universidade participante, pode-se inferir que os primeiro- anistas tinham pouco contato com o tema, pois há apenas três disciplinas (de natureza geral à formação em saúde) que podem discutir as deficiências que envolvem os seres humanos. Já, no segundo ano de graduação, há mais disciplinas que incorporam a temática da deficiência (políticas públicas de saúde e educação, bem como questões ligadas às ciências sociais, processo de aquisição e desenvolvimento humano, sobretudo, da linguagem em seus aspectos de regularidade e patologias), o que pode justificar o maior interesse dos estudantes nesta pesquisa.

No terceiro ano, os estudantes iniciam as práticas clínicas voltadas às questões de motricidade orofacial e de linguagem oral/fala, o que exigem deles maior disponibilidade e comprometimento no preparo dos processos avaliativos e terapêuticos por eles desenvolvidos, interferindo, assim, no tempo disponível para outras atividades que não a formação. No quarto ano, ampliam-se as atividades práticas nas diferentes áreas de atuação da Fonoaudiologia (audiologia, disfagia, equilíbrio, linguagem oral e/ou escrita; saúde coletiva [Aten- ção Primária e Secundária à Saúde] e voz), nas quais os estudantes dedicam-se aos atendimentos sob a supervisão de um professor da área. No quinto ano, os estudantes realizam Estágio Obrigatório em instituições extramuros (destaca-se que, na ocasião da coleta de dados desta pesquisa, havia apenas cinco estudantes nesta condição. Note-se que quatro estagiários responderam ao formulário/questionário $(80 \%$ do total, possivelmente por estarem realizando atividades em instituições que atendem pessoas com $\mathrm{PcD}$. Os quarto-anistas, ocuparam o segundo lugar em números absolutos. Condição também interpretada como influenciada pelas práticas clínicas.

Quanto à caracterização sociodemográfica dos respondentes, chama a atenção a prevalência do sexo feminino, a idade dos estudantes (entre 18 e 20 anos) e a constelação familiar (membros de famílias pequenas de classe econômica média). Tais características corroboram as encontradas em estudo, publicado em 2015, que pesquisou o perfil dos estudantes de Fonoaudiologia a partir do Exame Nacional de Desempenho de Estudantes (ENADE) de 2014 ${ }^{15}$.

Este estudo também revela a chamada "feminização da força de trabalho" "16. A propósito, o referido estudo ${ }^{15}$ destaca que as mulheres vêm ganhando espaço, inclusive, nas profissões de Odontologia e Medicina, anteriormente, procuradas majoritariamente por homens. Outro estudo ${ }^{17}$, também, destacou que em 14 cursos da área da saúde, incluindo a Fonoaudiologia, as mulheres eram a maioria com exceção da Medicina e da Educação Física. Tais pesquisas ${ }^{16,17}$ confirmam os dados evidenciados, no começo deste século XXI, pelo Índice Brasileiro de Geografia e Estatística (IBGE) ${ }^{18}$ que revelou que o maior percentual de concluintes do ensino superior, no Brasil, foi de mulheres.

Outro dado importante de ser destacado refere-se ao fato de a maioria dos estudantes advirem de escolas públicas e não terem tido, durante os anos escolares, contato com PcD e, tampouco, a oportunidade de discutir sobre o tema, apesar de já existir, na década de 90 do Século XX, a Declaração de Salamanca (1994) que recomendava a inclusão de $\mathrm{PcD}^{19}$. A propósito, segundo a $\mathrm{ONU}^{20}$, cerca de $90 \%$ das crianças com deficiência, de países em desenvolvimento, não frequentam escola - sejam públicas ou privadas. Tal situação é mais evidente nas escolas públicas que, ainda, enfrentam muitos problemas para promover a inclusão de PcD como, 
por exemplo, a falta de recursos materiais, pouca ou nenhuma formação dos educadores para lidarem com as diferenças e dificuldades para estabelecer comunicação $0^{21}$. As mesmas autoras advertem para mais um agravante, qual seja: muitos educadores consideram a deficiência somente como uma questão puramente orgânica, ou seja, como déficit físico, sensorial ou cognitivo, o que implica baixa expectativa dos docentes relacionada ao processo educacional da $\mathrm{PcD}^{21}$. Pode-se dizer, então, que os participantes deste estudo advêm de municípios que não realizaram oportunamente a inclusão de $\mathrm{PcD}$ nas escolas regulares (públicas ou privadas), mantendo-as nas escolas especiais ainda vigentes nos municípios onde estudaram até o Ensino Médio.

Chama atenção que o pouco contato dos participantes desta pesquisa com $\mathrm{PcD}$, também, ocorreu no contexto familiar (maioria de classe econômica média), demonstrando, mais uma vez, que os estudantes não vivenciaram situações inclusivas antes de iniciarem a formação em Fonoaudiologia. Quanto à classe econômica não foram encontrados estudos com estudantes deste núcleo profissional que a abordassem. Porém, pode-se aqui discutir os resultados a partir dos dados divulgados no último Censo do IBGE $^{18}$ que revelou que a maioria das PcD apresentam níveis de instrução (pouca escolaridade) e rendimentos muito baixos (classe econômica baixa), o que indica que o maior número de $\mathrm{PcD}$ pode estar entre as famílias menos instruídas e mais pobres, não configurando a realidade dos estudantes deste estudo. Conforme indicado anteriormente, a maioria dos acadêmicos se considerou pertencente à classe econômica média, já que tinham como opções as classes econômicas baixa, média e alta. Pode-se, ainda, destacar o Relatório Mundial sobre deficiência ${ }^{4}$ o qual destacou que, mundialmente, as PcD apresentam índices de problemas de saúde e de pobreza mais elevados devido às barreiras de acesso à saúde e educação, bem como ao emprego (salários e renda).

No que tange aos sentimentos e/ou às experiências de contato com PcD, a maioria dos estudantes referiu que vivenciou acontecimentos cotidianos positivos e agradáveis. Muitos referiram compartilhar "várias vezes ou frequentemente" espaços de lazer e de alimentação com PcD. A maioria, também, referiu que se disponibilizou para ajudar uma $\mathrm{PcD}$, mas nunca se deixou ser ajudado por uma PcD; tampouco conversou diariamente com uma e, menos ainda, abordou questões sobre de- ficiência com uma PcD. Tais dados podem estar revelando falhas na efetiva inclusão social dessas pessoas, o que indica descompasso entre o que se sabe que deve ser feito e o que realmente se faz. Essas situações podem decorrer de fatores contextuais estereotipados como a presença de aspectos limitantes, por exemplo, condições individuais (tanto da PcD como da pessoa sem deficiência) e do ambiente físico e social, pois os comportamentos ainda são marcados por crenças na desigualdade, na desqualificação ou desvalorização das PcD enquanto sujeitos sociais ${ }^{22}$. Estas autoras ${ }^{22}$ não deixam de indicar que as atitudes (da sociedade em geral) podem ser mantidas por profissionais que lançam mão de modelos assistencialistas e excludentes, fato que ampliam as desvantagens sociais da PcD. A este respeito pode-se dizer que os processos terapêuticos não realizam atividades externas ao ambiente clínico de modo a promover a inclusão e nem a incentiva fora desse contexto.

Sabe-se que a formação acadêmica em Fonoaudiologia requer o envolvimento com a temática das deficiências e, por isso, não deve se limitar às técnicas terapêuticas, mas devem desenvolver habilidades, atitudes e valores éticos do futuro profissional. Em virtude disso, os processos de ensino-aprendizagem devem ser (re)construídos envolvendo educadores, educandos, órgãos responsáveis pela saúde, educação e/ou assistência às $\mathrm{PcD}$ e, certamente, a sociedade. Concorda-se, aqui, que a formação profissional deve favorecer a autocrítica e a responsabilidade social dos estudantes, bem como incentivar a busca por relações interdisciplinares para o enfrentamento de situações variadas e, muitas vezes, adversas ${ }^{23}$.

A análise das respostas revelou que a maior parte dos acadêmicos concorda totalmente com as assertivas relativas à formação sobre deficiências. No entanto, a maioria indicou a insuficiência quanto ao detalhamento das políticas públicas acerca das PcD e quanto à atuação ampla junto a tais pessoas, apesar de, na grade curricular do curso de Fonoaudiologia, existirem disciplinas voltadas às políticas públicas de saúde e de educação. Destaca-se, aqui, que dentre as políticas de saúde, passíveis de participação da Fonoaudiologia, não está explicitado, no plano de ensino, a Política Nacional de Saúde da $\mathrm{PcD}^{24}$; já quanto à Educação, tem-se destacada a de Educação Especial25.

A limitação dos acadêmicos para lidarem com a deficiência, também, apareceu refletida nas atitu- 
des deles quanto ao voluntariado. Pode-se, então, inferir que os limites apontados pelos estudantes decorrem, por um lado, do não conhecimento das diversas políticas voltadas a PcD e, por outro, da restrita oportunidade de práticas clínicas junto a elas, pois, sabe-se que uma formação ampliada requer conhecimento e aplicação dos direitos das PcD como, também, a transposição dos conceitos adquiridos nas diferentes áreas da Fonoaudiologia que se aplicam ao cuidado das $\mathrm{PcD}$. A propósito, os acadêmicos devem ser preparados para verem os usuários em sua totalidade e nas suas subjetividades de interação entre espaços (físicos e sociais) que vivem. Estarem preparados para observar esses fatores, certamente, proporcionará ao discente um melhor intercâmbio com os envolvidos no processo $(\mathrm{PcD} \text {, seus familiares, educadores, entre outros })^{23}$. $\mathrm{PcD}$ se sentem limitadas e impotentes frente às realidade vivenciadas, assim, tanto os profissionais da saúde, quanto a rede de apoio dessas pessoas, devem estar atentos aos aspectos físicos, mas, também, às percepções subjetivas das mesmas ${ }^{26}$.

Além do explicitado acima, o futuro do profissional de Fonoaudiologia, segundo as Diretrizes Curriculares Nacionais instituídas pelo Conselho Nacional de Educação e Câmara de Educação Superior ${ }^{27}$ deve ser generalista, humanista, crítico e reflexivo; com atuação pautada em princípios éticos, seja no campo clínico-terapêutico, seja no preventivo. Assim, no que tange às deficiências, deve ser competente no reconhecimento das necessidades de saúde das $\mathrm{PcD}$, ou seja, observar e atuar sobre suas particularidades, entendendo, pois, que são as relações com meio físico e social que determinam o grau de incapacidade e/ou de funcionalidade de uma pessoa ${ }^{4}$.

Outro dado que merece discussão é o relativo ao grau de dificuldade dos estudantes em se relacionar com PcD. Note-se que a faixa etária em que os acadêmicos indicaram "menor dificuldade ou nenhuma" foi a de crianças. A faixa etária adulta foi a que os estudantes indicaram ter "maior dificuldade". Tais dados, de certo modo, concordam com um estudo ${ }^{28}$ que indica que as crianças são as que mais recebem atendimento em Fonoaudiologia. A propósito, as práticas clínicas ofertadas no curso, ainda, contam com maior número de crianças em processos terapêuticos por dificuldades/distúrbios de linguagem oral/fala, escrita, motricidade orofacial, e auditiva.
Quanto ao tipo de deficiência, a de natureza psiquiátrica (também possível de ser identificada como doença mental) foi a indicada, pelos acadêmicos, como a de maior dificuldade, seguida da deficiência visual. Quanto às dificuldades de natureza psiquiátrica, estas são abordadas teoricamente na grade curricular do curso e as práticas clínicas, que oportunizam contato com pessoas com necessidades de atenção à saúde mental, restringem-se a um único campo, sendo que os Centros de Atendimento Psicossocial (CAPS), especialmente CAPSi (infantil), do município não contam com a atuação de fonoaudiólogos que respondam às necessidades do curso, fato que prejudica a formação nesta área. Estudo $^{29}$ refere à importância da participação da Fonoaudiologia nas equipes multiprofissionais da saúde mental, ressaltando o papel do fonoaudiólogo como profissional privilegiado para diagnosticar e/ou aprimorar as formas de expressão de sujeitos em sofrimento, seja realizando avaliações ou intervenções terapêuticas (acompanhamentos longitudinais).

Já em relação à deficiência visual, são escassos os estudos que referem à participação da Fonoaudiologia. Monteiro e Montilha ${ }^{30}$ recomendam o atendimento fonoaudiológico a pessoas com deficiência visual indicando estimulação de localização e reconhecimento de sons (especialmente ambientais) para o aprimoramento da orientação, mobilidade e proteção dessas pessoas. Também destacam a possibilidade de o fonoaudiólogo trabalhar os aspectos relacionados à motricidade orofacial, de modo a contribuir na melhoria das habilidades orais e de comunicação e, ainda, trabalhar com outros aspectos que favorecem as atividades de vida diária.

A partir deste ponto, discute-se a situação hipotética e passível de vivência entre uma PcD e outra sem (Cláudia ou José - protagonista da situação), sendo recomendado a indicação do sexo da PcD. Foi possível identificar que a maioria dos respondentes (do sexo feminino) projetou a deficiência no sexo masculino. Segundo Crochick $^{31}$, pessoas que possuem preconceitos tendem a projetar seus sentimentos e suas impotências em objetivos externos. De certa forma, tal afirmação pode ser aproximada dos resultados deste estudo, visto que houve projeção da deficiência no sexo oposto - não sendo possível identificar se essa projeção foi por preconceito, por falta de aproximação dos estudan- 
tes a PcD e/ou pela escassa discussão acerca das deficiências durante a graduação.

Conforme dito anteriormente, durante tal situação, os estudantes poderiam experimentar diferentes sentimentos, pensamentos e comportamentos. Discutem-se, aqui (por limites de extensão textual), apenas os dados referentes aos "prováveis de acontecerem", independentemente da graduação (bem, altamente e totalmente provável). Em relação aos sentimentos, pode-se constatar alto percentual de timidez $(83,32 \%)$, seguido de tensão $(72,22 \%)$, impotência, vergonha e nervosismo $(63,88 \%)$. Pode-se, então, dizer que, assim como afirmam clássicos estudos ${ }^{31,32}$, imaginar vivências com $\mathrm{PcD}$ tende a produzir ambiguidades, ansiedades e medos frente a situações consideradas diferentes. A tensão e a impotência, por exemplo, podem decorrer da sensação de que não é possível lidar com a deficiência que, por sua vez, pode advir da crença de que as PcD são incapazes e frágeis ${ }^{32}$. No entanto, sob a ótica dos direitos humanos, as incapacidades devem ser interpretadas como uma questão política e a superação das mesmas requer ações coletivas voltadas à eliminação de barreiras físicas e atitudinais ${ }^{3}$. Concordando-se com tais estudos $^{32,3}$, há que se intensificar a concepção de direitos humanos durante a formação profissional, visando-se ampliar as condições dos estudantes para ação junto e com as $\mathrm{PcD}$.

Quanto aos pensamentos, a maioria dos acadêmicos referiu que todos os listados seriam passíveis de acontecer, com variação no grau das probabilidades, exceto o pensamento que revela agradecimento da $\mathrm{PcD}$ à pessoa sem deficiência por iniciar uma conversa (metade revelou que seria bem provável de acontecer e metade a de não acontecer). Disso, pode-se extrair a compreensão de que metade dos estudantes (grupo que relatou menor ou nenhuma probabilidade de acontecer) entende-se realmente comprometido e a outra metade (grupo que marcou "provável; altamente provável e/ou totalmente provável) entende-se benevolente com as PcD. O que diferencia um grupo do outro é o fato de que o primeiro indica uma atitude profissionalizada (convivência não requer agradecimento de nenhuma parte envolvida, já que se trata de um processo natural do humano) e o segundo a uma atitude leiga (convivência com PcD é suportável por suas fragilidades).

Em relação aos comportamentos, dentre os passíveis de acontecer, destaca-se que a maioria dos acadêmicos assinalou que iniciaria uma conversa, mas houve aqueles que optaram por ignorar a PcD (leitura de jornal, conversa ao celular e/ ou manutenção do que estava fazendo). $\mathrm{O}$ fato de muitos continuarem o que estavam fazendo e/ou então buscarem uma distração (ler jornal ou falar ao celular) remete ao comportamento - afastamento/ exclusão da PcD. A não identificação com o outro e/ou a não convivência são mecanismos de negação social ${ }^{31}$, que implica a retirada da possibilidade de a PcD se manter-se sujeito de convivência. O referido comportamento excludente remete que podem estar ainda presentes, no campo da formação acadêmica, os modelos assistencialistas de atenção às $\mathrm{PcD}$, reforçados pelas instituições especializadas (escolas especiais) ${ }^{32}$ que entendem que as $\mathrm{PcD}$ precisam ser tratadas/curadas/ normatizadas ${ }^{33}$.

Nota-se a contradição de comportamentos, de modo que se pode inferir que há um distanciamento entre o que o acadêmico pensa e como se comporta, demonstrando que os sentimentos iniciais de estranheza interferem no contato com a PcD e se mantêm quando não há a oportunidade de formação que privilegie a interação entre $\mathrm{PcD}$ e sem deficiência ${ }^{31}$. A não visibilidade da $\mathrm{PcD}$, seja por paradigmas históricos e excludentes ${ }^{22}$, seja por afastamento, medo, estranheza ou hostilidade ${ }^{31}$ são barreiras a serem vencidas por meio de contato direto (pessoal) e marketing (social), ou seja, por meio da correta inclusão social ${ }^{34}$. Estudos realizados em outros núcleos profissionais ${ }^{9,10,11}$ também relataram que a insegurança, as dificuldades e os medo dos estudantes frente às $\mathrm{PcD}$, foram superados pela busca de informações, aquisição de conhecimentos e envolvimento direto com as PcD. Enfatiza-se, assim, a importância de experiências com $\mathrm{PcD}$ e de disciplinas referentes às deficiências durante a graduação, visto que dessa relação experiência/ conhecimento pode-se alcançar a formação profissional (técnica e socialmente desejada) para atuar junto à $\mathrm{PcD}$.

Neste sentido, a identificação/a visibilidade das PcD só é possível por meio da convivência, da efetivação de atitudes e de ações dos profissionais que promovam a superação das crenças pejorativas, construindo-se, por todos os meios, as condições de equidade nas várias instâncias da vida social ${ }^{22}$. 


\section{Conclusão}

Este estudo possibilitou identificar as percepções e as atitudes de estudantes de Fonoaudiologia sobre $\mathrm{PcD}$, futuros profissionais, que certamente se ocuparão do cuidado e da inclusão social dessas pessoas. A participação dos estudantes foi pequena (aproximadamente $45 \%$ ) e não foi equilibrada entre os cinco anos da graduação.

Os acadêmicos tiveram pouco contato, prévio à graduação, com $\mathrm{PcD}$. No que tange à formação profissional, demonstraram a percepção de que não se sentem suficientemente preparados para atuarem de forma ampla com as PcD. Informaram terem formação mínima para atuação junto a tais pessoas e indicaram a necessidade de complementar a formação com a intersecção das políticas públicas voltadas às $\mathrm{PcD}$ (destacando os seus direitos), bem como de ampliar as experiências práticas junto às $\mathrm{PcD}$. Revelaram maior dificuldade para se relacionarem com pessoas com problemas de natureza psiquiátrica.

Os acadêmicos, de modo geral, demonstraram contradições entre seus sentimentos, pensamentos e comportamentos relativos à convivência e/ou atuação junto à $\mathrm{PcD}$. Neste sentido, sugere-se o aprofundamento da investigação nesta área, com maior número de participantes, visando-se aprimorar a formação acadêmica em Fonoaudiologia voltada às $\mathrm{PcD}$, inclusive, comprometida com a inclusão social de tais pessoas.

\section{Referências}

1. OMS. Classificação Internacional de Funcionalidade, Incapacidade e Saúde. Lisboa, Direção Geral de Saúde, 2004.

2. Braddock DL, Parish SL. An Institutional History of Disability. In: Albrecht GL, Seelman KD, Bury, M, editors. Hand book of Disability Studies. London: Sage; 2001; p. 11-68.

3. Ali M, Schur L, Blanck P. What types of jobs do people with disabilities want? Journal of Occupational Rehabilitation, 2011; 21(2), 199-210

4. OMS. Relatório Mundial sobre Deficiência. Publicado pela Organização Mundial da Saúde sob o título World Report on Disability. 2011.

5. Smedema, SM, Kesselmayer, RF, \& Peterson, L. Evaluation of a multiple mediator model of the relationship between core self-evaluation sand job satisfactions in employed individuals with disabilities. Rehabilitation Research Policy and Education, 2018; 32(2), 139-154.

6. Terzi L. Reframing inclusive education: education ale quality as capability equality. Cambridge Journal of Education, 2014; 44(4), 479-493.
7. Gil AC. Métodos e técnicas de pesquisa social. 4 ed. São Paulo: Atlas, p. 207. 1994.

8. Findler L, Vilchinsky N, Werner S. The Multidimensional Attitudes Scale Toward Persons With Disabilities (MAS): construction and validation. 2007, RCB 50: 3 pp. 166-176.

9. Ryan TA, \& Scior K. Medical students' attitudes towards people with intellectual disabilities: A literature review. Research in Developmental Disabilities, 2014; 35(10), 23162328. doi:10.1016/j.ridd.2014.05.019.

10. Rebouças CBA, et al. Pessoa com deficiência física e sensorial: percepção de alunos da graduação em enfermagem. Acta Paul Enferm. 2011; 24(1): 80-6.

11. Ferreira HS et al. Percepção de estudantes de graduação em Odontologia frente ao atendimento de pessoas com deficiência. Revista da ABENO, 2017, 17(1): 87-96.

12. OMS. CID-10- Classificação Internacional de Doenças, 1990.

13. Vasconcellos-Guedes L, Guedes LFA. Vantagens e Limitações dos Questionários Eletrônicos via Internet no Contexto da Pesquisa Científica. In: X SemAd - Seminário em Administração FEA/USP (São Paulo, Brasil), 2007.

14. Granado JIF, et al. Integração acadêmica de estudantes universitários: contributos para a adaptação e validação do QVA-r no Brasil. Psicologia e Educação, Portugal, Universidade da Beira Anterior, v. 4, n. 2, p. 33-43, 2005.

15. Santos ACM, Luccia G. Perfil dos estudantes de fonoaudiologia segundo o Exame Nacional de Desempenho de Estudantes. Revista Distúrbios Comunicação Humana. São Paulo, 2015, 27(3): 589-599.

16. Matos IB, Toassi RFC, Oliveira MC de. Profissões e ocupações da Saúde e o processo de feminização: Tendências e implicações. Athenea Digital, 2013; 13(2) 239-244.

17. Haddad AE, et al. Formação de profissionais de saúde no Brasil: uma análise no período de 1991 a 2008. Rev. Saúde Pública [online]. 2010, vol.44, n.3, pp.383-393. https://doi. org/10.1590/S0034-89102010005000015.

18. IBGE. Censo Demográfico 2010: Banco de Dados agregados do IBGE. Rio de Janeiro, 2010. [acesso em 2020 julho 23] Disponível:http://www.ibge.gov.br/home/estatistica/populacao/ censo2010/default.shtm.

19. UNESCO. Declaração de Salamanca. Conferência Mundial sobre Educação Especial. Salamanca-Espanha, 1994.

20. ONU, Brasil (2015). A ONU e as pessoas com deficiência. [acesso em 2020, Julho 27]. Disponível em: https://nacoesunidas. org/acao/pessoas-com-deficiencia/.

21. Monteiro MB, Camargo EAA, Freitas AP. Reflexões sobre práticas de ensino e inclusão. Journal of Research in Special Educational Needs. Volume 16 Number s1, 2016, 940-944.

22. Mazzotta MJS, D’antino MEF. Inclusão social de pessoas com deficiências e necessidades especiais: cultura, educação e lazer. Saúde soc. vol.20 nº 2, São Paulo Abril/Junho, 2011, p.377-389.

23. Ribeiro Il, Medeiros Junior A. Graduação em saúde: uma reflexão sobre ensino-aprendizado. Trab. educ. saúde. 2016; 14(1): 33-53.

24. Brasil. Política Nacional de Saúde da Pessoa com Deficiência. 2002. [acesso em 2020, Agosto 4]. Disponível em http://bvsms.saude.gov.br/bvs/publicacoes/politica_nacional pessoa_com_deficiencia.pdf. 
25. Brasil. LEI N ${ }^{\circ} 9.394$ de 20 de dezembro de 1996. Estabelece as diretrizes e bases da educação nacional. [Acesso em 2020, Agosto 1] Disponível em: http://portal.mec.gov.br/seesp/ arquivos/pdf/lei9394_ldbn1.pdf.

26. Pereira MGL. Do Sonho À Realidade: O Impacto Da Deficiência No Âmbito Familiar. Psicologia.pt. ISSN 2018, 1646-6977.

27. Brasil. Resolução CNE/CES 5 de 19 de fevereiro de 2002. Institui Diretrizes Curriculares Nacionais do Curso de Graduação em Fonoaudiologia. Diário Oficial da União.4 mar 2002; Seção3:165.

28. Diniz RD, Bordin R. Demanda em Fonoaudiologia em um serviço público municipal da região Sul do Brasil. Rev. Soc. Bras. Fonoaudiologia 2011;16(2): 126-31.

29. Evangelista VN. Transtorno do espectro autista e a fonoaudiologia na rede de atenção psicossocial. [Trabalho de conclusão de curso]. Universidade Federal Da Bahia. Instituto De Ciências Da Saúde, 2018, Salvador- Bahia.

30. Monteiro MMB, Montilha RCI. Intervenção fonoaudiológica e a deficiência visual: percepções de profissionais de equipe interdisciplinar. Medicina (Ribeirão Preto) 2010; 43(1): 11-19

31. Crochik, JL. Perspectivas teóricas acerca do preconceito. São Paulo: Casa do Psicólogo. 2007

32. Silva, LM. O estranhamento causado pela deficiência: preconceito e experiência. Revista Brasileira de Educação, Rio de Janeiro, 2006, v. 11, n. 33, p. 424-434.

33. Sassaki RK. Inclusão: construindo uma sociedade para todos Rio de Janeiro, WVA (3 ${ }^{\mathrm{a}}$ ed.) 1999.

34. Thornicroft G, Brohan E, Kassam A, Lewis-Holmes E. Reducing stigma and discrimination: Candidate interventions. International Journal of Mental Health Systems, 2008, 2:3- doi: 10.1186/1752-4458-2-3 PMID: 18405393. 